The Last Word

Mariela A. Blum Murphy, MD

Mariela A. Blum Murphy, MD, is an Assistant Professor of Medicine in the Department of Gastrointestinal Medical Oncology, University of Texas MD Anderson Cancer Center. She earned her medical degree from the Universidad Cátolica de Santiago de Guayaquil, Ecuador in 2003. She then completed an Internal Medicine Residency program at Jackson Memorial Hospital, University of Miami, Florida, and pursued further training in Hematology and Oncology at the Baylor College of Medicine in Houston, Texas. Her clinical research interests are in patients with gastric and esophagea cancer.

Takashi Taketa, MD

Takashi Taketa, MD, is from the Department of Gastrointestinal Medical Oncology, The University of Texas MD Anderson Cancer Center, Houston, Texas.

Kazuki Sudo, MD

Kazuki Sudo, MD, is from the Department of Gastrointestinal Medical Oncology, The University of Texas MD Anderson Cancer Center, Houston, Texas.

Jeffrey $\mathrm{H}$. Lee, MD, MPH

Jeffrey H. Lee, MD, MPH, is Professor, Department of Gastroenterology, Hepatology, and Nutrition, at the University of Texas MD Anderson Cancer Center, Houston, Texas.

\section{Surveillance for Esophageal Cancer: Does it Make Sense?}

\author{
Mariela A. Blum Murphy, MD; Takashi Taketa, MD; Kazuki Sudo, MD; \\ Jeffrey H. Lee, MD, MPH; and Jaffer A. Ajani, MD
}

The main objective of screening for high-risk conditions is to diagnose them at an early stage and improve the likelihood of cure. Although this is a seemingly simple concept, is requires navigation through a complex set of circumstances innate in current societies. These complexities include relatively high prevalence of the targeted condition, simplicity with which surveillance can be accomplished, low or absent complication rates, high sensitivity and specificity of the test for screening, and, finally, the perception by the public that it is a cost-effective test coupled with low intrusiveness. In the cancer arena, we can point to relative successes (colorectal and breast cancer screening) and a relative failure (all the debates about the lack of merit for prostate cancer screening).

Additionally, some screening principles can be questioned: Should every adult be considered "at risk"? Can nongenetic test models (based on ethnicity, geographic residence, environment, and lifestyle variables) be developed to enrich a population for targeted surveillance? Is it practical to develop and implement a model that would include genetic susceptibility elements with environmental and lifestyle elements? This commentary discusses the answers to these questions in the context of esophageal cancer (EC).

EC merits this type of discussion because of its high incidence in many regions of the world and its impact on global health. EC is the eighth most common cancer worldwide, with an estimated 407,000 deaths in 2008. ${ }^{1}$ EC is often diagnosed at an advanced stage. Therefore, outcomes continue to be dismal. In this setting, one can assume that screening for EC would make sense.

The majority of ECs are squamous cell carcinoma (SCC), but adenocarcinoma (AC) is increasing in incidence. ${ }^{2-5} \mathrm{SCC}$ is common in the endemic areas, and AC is more frequently found in the Western world. The highest rates of SCC are seen in the Central Asian "EC belt." This region includes the countries of the Caspian littoral, the central Asian republics, Mongolia, and northwestern China.

Preneoplastic squamous cell dysplasia is often attributed to tobacco use, alcohol consumption, and decreased intake of fruits and vegetables. ${ }^{6,7}$ Patients with an inactive aldehyde dehydrogenase-2 genotype (present in 20\%-30\% of the Japanese population) are at a high risk of developing SCC. ${ }^{8}$ The identification of susceptibility gene loci related to alcohol and tobacco is important progress in determining the genetic underpinnings of SCC. ${ }^{9}$ In the endemic regions of China, balloon cytology was initially used to detect SCC early, but it is no longer a common practice, and no routine screening for SCC is currently performed. This lack of screening is unfortunate, because an aggressive and a strategic approach can save lives in endemic regions.

Surveillance for $\mathrm{AC}$ poses unique challenges. The only known premalignant condition for AC is Barrett's esophagus (BE). BE is defined as specialized intestinal metaplasia of the distal tubular esophagus. In Western societies, where the average adult body mass index is increasing, the prevalence of gastroesophageal reflux disease and consequent $\mathrm{BE}$ has increased at an alarming pace. Screening for BE is recommended in white men 50 years of age and older who have frequent (several times per week) and longstanding gastroesophageal reflux disease ( $>5$ years) along with high body mass index or nocturnal reflux..$^{10}$

However, recent literature confirms that the rate of progression from $\mathrm{BE}$ to $\mathrm{AC}$ is as low as $0.18 \%$ per year. ${ }^{11,12}$ This low rate suggests a need for caution when considering
The ideas and viewpoints expressed in this editorial are those of the author and do not necessarily represent any policy, position, or program of NCCN. 
surveillance for AC. That the incidence of AC has increased over the past several decades is unquestioned, but this increase may be due to the high prevalence of $\mathrm{BE}$ or other undefined factors. Thus, the cost-effectiveness of screening must be questioned, because only a few patients with $\mathrm{BE}$ will develop AC.

We acknowledge that patients with $\mathrm{BE}$ with high-grade dysplasia (HGD) remain at higher risk of developing $\mathrm{AC}$ than those with $\mathrm{BE}$ without HGD or those with low-grade dysplasia. Therefore, therapy should be recommended for patients diagnosed with HGD. For localized HGD, endoscopic therapies seem successful, and surgery is rarely needed. However, this situation begs the question, is surveillance warranted in patients with BE without HGD? Current guidelines are based on expert recommendations or retrospective studies; well-designed prospective trials with AC as a primary end point are lacking. For patients with BE without dysplasia, endoscopy every 3 years is suggested, and for patients with low-grade dysplasia, endoscopy every 6 to 12 months is suggested. ${ }^{10,13,14}$

Furthermore, these recommendations are for patients with BE, but what if an adult has not been diagnosed with BE? We believe the need exists for a model that incorporates genetic susceptibility traits and lifestyle traits to survey targeted populations at high risk for developing AC. If such a model is initially successful, then its efficacy (reduction in AC mortality) and cost-effectiveness must be established before it can be recommended for widespread use.

Assuming a model is developed that can be implemented in high-risk populations, another challenge is implementing it in the target population. This is not a small challenge. We can examine the tools available for surveillance of EC. The gold standard method for diagnosing EC and BE is esophagogastroduodenoscopy. However, this procedure is costly and associated with cardiopulmonary risks, although those risks are small. ${ }^{15,16}$ An alternative procedure is ultrathin transnasal endoscopy, which is feasible in the office and has low risks and low costs. ${ }^{17-20}$ Obtaining small biopsies through transnasal endoscopy is a compromise, ${ }^{21}$ but one that can be equally as efficacious as esophagogastroduodenoscopy. ${ }^{22-24}$

In conclusion, screening is recommended for SCC in endemic areas; however, determining effectiveness and best practices must be accomplished through wellconceived prospective trials. This screening would be worthwhile, because a large number of subjects are at risk. For patients with BE, existing guidelines seem helpful; however, for most adults who have not been diagnosed with $\mathrm{BE}$, surveillance for $\mathrm{AC}$ cannot be recommended. Clearly, further research is warranted, and we recommend the goal of creating a model that incorporates genetic susceptibilities and lifestyle elements. This model can then be applied to high-risk populations for targeted surveillance.

Multiple other opportunities lie ahead, including in-depth characterization of genetic susceptibilities; outcome correlation with circulating mRNAs, small RNAs, DNA fragments, and protein/peptide molecules; and molecular studies of the target tissues themselves.

\section{References}

1. Jemal A, Bray F, Center MM, et al. Global cancer statistics. CA Cancer J Clin 2011;61:69-90.

2. Jemal A, Center MM, DeSantis C, Ward EM. Global patterns of cancer incidence and mortality rates and trends. Cancer Epidemiol Biomarkers Prev 2010;19:1893-1907.

3. Pohl H, Sirovich B, Welch HG. Esophageal adenocarcinoma incidence: are we reaching the peak? Cancer Epidemiol Biomarkers Prev 2010;19:1468-1470.

4. Lepage $\mathrm{C}$, Rachet $\mathrm{B}$, Jooste $\mathrm{V}$, et al. Continuing rapid increase in esophageal adenocarcinoma in England and Wales. Am J Gastroenterol 2008;103:2694-2699.
Jaffer A. Ajani, MD

Jaffer A. Ajani, MD is from the Department of Gastrointestinal Medical Oncology, The University of Texas MD Anderson Cancer Center, Houston, Texas.

This work was supported in part by the Dallas, Park, Smith, and Cantu family funds, the Kevin Fund; the Sultan Fund; the River Creek Foundation; and the Aaron and Martha Schecter Private Foundation. This work was also supported by the Multidisciplinary Research Program at MD Anderson and by the National Institutes of Health through MD Anderson's Cancer Center Support Grant CA016672. 
Blum Murphy et al

5. Devesa SS, Blot WJ, Fraumeni JF Jr. Changing patterns in the incidence of esophageal and gastric carcinoma in the United States. Cancer 1998;83:2049-2053.

6. Brown LM, Swanson CA, Gridley G, et al. Dietary factors and the risk of squamous cell esophageal cancer among black and white men in the United States. Cancer Causes Control 1998;9:467-474.

7. Thun MJ, Peto R, Lopez AD, et al. Alcohol consumption and mortality among middle-aged and elderly US adults. N Engl J Med 1997;337:1705-1714.

8. Yokoyama A, Oda J, Iriguchi Y, et al. A health-risk appraisal model and endoscopic mass screening for esophageal cancer in Japanese men. Dis Esophagus 2012, in press.

9. Wu C, Hu Z, He Z, et al. Genome-wide association study identifies three new susceptibility loci for esophageal squamous-cell carcinoma in Chinese populations. Nat Genet 2011;43:679-684.

10. Spechler SJ, Sharma P, Souza RF, et al. American Gastroenterological Association medical position statement on the management of Barrett's esophagus. Gastroenterology 2011;140:1084-1091.

11. Sikkema M, de Jonge PJF, Steyerberg EW, Kuipers EJ. Risk of esophageal adenocarcinoma and mortality in patients with Barrett's esophagus: a systematic review and meta-analysis. Clin Gastroenterol Hepatol 2010;8:235-244.

12. Yousef F, Cardwell C, Cantwell FF, et al. The incidence of esophageal cancer and high-grade dysplasia in Barrett's esophagus: a systematic review and meta-analysis. Am J Epidemiol 2008;168:237-249.

13. Hirota WK, Zuckerman MJ, Adler DG, et al. ASGE guideline: the role of endoscopy in the surveillance of premalignant conditions of the upper GI tract. Gastrointest Endosc 2006;63:570-580.

14. Fornari F, Wagner R. Update on endoscopic diagnosis, management and surveillance strategies of esophageal diseases. World J Gastrointest Endosc 2012;4:117-122.

15. Sharma VK, Nguyen CC, Crowell MD, et al. A national study of cardiopulmonary unplanned events after GI endoscopy. Gastrointest Endosc 2007;66:27-34.

16. Lieberman DA, Wuerker CK, Katon RM. Cardiopulmonary risk of esophagogastroduodenoscopy: role of endoscope diameter and systemic sedation. Gastroenterology 1985;88:468-472.

17. Dean R, DuaK,MasseyB, etal.Acomparativestudy ofunsedated transnasalesophagogastroduodenoscopy and conventional EGD. Gastrointest Endosc 1996;44:422-424.

18. Bampton PA, Reid DP, Johnson RD, et al. A comparison of transnasal and transoral oesophagogastroduodenoscopy. J Gastroenterol Hepatol 1998;13:579-584.

19. Craig A, Hanlon J, Dent J, Schoeman M. A comparison of transnasal and transoral endoscopy with small-diameter endoscopes in unsedated patients. Gastrointest Endosc 1999;49:292-296.

20. Peery AF, Hoppo T, Garman KS, et al. Feasibility, safety, acceptability, and yield of office-based, screening transnasal esophagoscopy (with video). Gastrointest Endosc 2012;75:945-953.

21. Lao-Sirieix P, Fitzgerald RC. Screening for oesophageal cancer. Nat Rev Clin Oncol 2012;9:278-287.

22. Saeian K, Townsend WF, Rochling FA, et al. Unsedated transnasal EGD: an alternative approach to conventional esophagogastroduodenoscopy for documenting Helicobacter pylori eradication. Gastrointest Endosc 1999;49:297-301.

23. Saeian K, Staff D, Knox J, et al. Unsedated transnasal endoscopy: a new technique for accurately detecting and grading esophageal varices in cirrhotic patients. Am J Gastroenterol 2002;97:22462249.

24. Saeian K, Staff DM, Vasilopoulos S, et al. Unsedated transnasal endoscopy accurately detects Barrett's metaplasia and dysplasia. Gastrointest Endosc 2002;56:472-478. 